\title{
EGU2020-11671
}

https://doi.org/10.5194/egusphere-egu2020-11671

EGU General Assembly 2020

(c) Author(s) 2021. This work is distributed under

the Creative Commons Attribution 4.0 License.

\section{Sediment connectivity in Alpine basins: from isolated storms to turbidity currents in deep peri-Alpine lakes (examples from the Rhône basin and Lake Geneva, Switzerland)}

\author{
François Mettra ${ }^{1,2}$, Koen Blanckaert ${ }^{3}$, Ulrich Lemmin ${ }^{4}$, and David Andrew Barry ${ }^{4}$ \\ ${ }^{1}$ Université de Lausanne, IDYST, Lausanne, Switzerland (francois.mettra@unil.ch) \\ ${ }^{2}$ Invited researcher at Institute of Hydraulic Engineering and Water Resources Management, TU Wien, Karlsplatz 13/222, \\ A-1040 Vienna \\ ${ }^{3}$ Institute of Hydraulic Engineering and Water Resources Management, TU Wien, Karlsplatz 13/222, A-1040 Vienna \\ ${ }^{4}$ Ecological Engineering Laboratory, Lausanne Federal Institute of Technology, Station 2, CH-1015 Lausanne
}

In the main river canyon of a deep peri-Alpine lake (Rhône River canyon in Lake Geneva, Switzerland), occasional turbidity currents have been observed and monitored using acoustic Doppler current profilers (ADCP) during summer. It has been hypothesized that floods at catchment basin scale and slides of sublacustrine deltaic deposits are the main cause of these turbidity currents. Here, using discharge and turbidity measurements in the Rhône River, $6 \mathrm{~km}$ upstream of Lake Geneva and observations from small sub-catchments (as small as $4 \mathrm{~km}^{2}$ ), we show that single isolated storms in such sub-catchments can lead to turbidity currents in the deep Lake Geneva without a significant flood th the catchment basin scale $\left(\sim 5500 \mathrm{~km}^{2}\right)$.

We analyzed several examples of hyper-concentrated and debris flows generated in small subcatchments, reaching the Rhône channel and leading to turbidity currents in Lake Geneva. The relatively high discharge of the Rhône River and its straight man-made channel induced a rapid and intense transfer of sediment toward Lake Geneva. The continuous measurements in the Rhône River allowed tracking these sediment clouds and estimating sediment volumes. Then, using the ADCP measurements, we were able to mesure the intensity of the subsequent sediment pulses in the form of turbidity currents inside the Rhône River canyon in the deep part of Lake Geneva.

In summary, this study shows that a significant fraction of the annual sediment yield of the whole catchment basin is released from specific high-alpine areas due strong but localized storms. These sub-catchments have the specificity to be highly connected with the main channel of the catchment basin, thus permitting a rapid transfer along the sediment cascade (in one single event). 